\title{
Effect of Hydrogen on Diffusion Bonding Behavior and Mechanism of Ti-6Al-4V alloy
}

\author{
Li Zhiqiang ${ }^{1,2}, \quad$ Han Kun², $\quad$ Hou Hongliang ${ }^{2}, \quad$ Wang Baoyu', Hu Zhenhuan' \\ ${ }^{1}$ University of Science and Technology Beijing, Beijing 100083, China; ${ }^{2}$ Beijing Aeronautical Manufacturing Technology Research Institute, \\ Beijing 100024, China
}

\begin{abstract}
The hydrogenated commercially pure titanium and Ti-6AL-4V alloy with $0.11 \mathrm{wt} \% \mathrm{H}$ were diffusion-bonded in the temperature range from 800 to $860{ }^{\circ} \mathrm{C}$. The interface and elements diffusion were observed by OM, SEM and EPMA. The results show that hydrogen significantly improves the rate of diffusion bonding (bonding rate is up to $98 \%$ under the condition of $0.11 \mathrm{wt} \% \mathrm{H}$ at $\left.840{ }^{\circ} \mathrm{C}\right)$. An equiaxed microstructure is maintained due to the addition of $0.11 \mathrm{wt} \% \mathrm{H}$ after bonding while the higher amount of hydrogen $(0.32 \mathrm{wt} \% \sim 0.48 \mathrm{wt} \% \mathrm{H})$ results in a coarse widmanstatten structure. The improved performance of the diffusion bonding induced by hydrogen is mainly attributed to the weak-bond effect and the increase of diffusion coefficient of the elements. The addition of $0.11 \mathrm{wt} \% \mathrm{H}$ brings one order increase of magnitude to the diffusion coefficient of $\mathrm{Al}$ and $\mathrm{V}$ element, as well as $40{ }^{\circ} \mathrm{C}$ lower diffusion bonding temperature compared with non-hydrogen Ti-6Al-4V alloy.
\end{abstract}

Key words: hydrogen; Ti-6Al-4V; diffusion bonding

SPF/DB (superplasitic forming/diffusion bonding) is near-net shaping and bonding technology, which promotes the concept of the integrated metallic structure in aerospace industry and breaks through the traditional method of sheet metal forming. However, due to the high melting point of titanium, its diffusion bonding temperature is higher than $860{ }^{\circ} \mathrm{C}$, which requires high temperature resistance die materials and increases manufacturing cost. The way how to reduce the bonding temperature becomes the key issue to maintain the competitiveness of SPF/DB technology.

Studies have shown that titanium thermohydrogen processing (THP for short) can effectively reduce the diffusion bonding temperature ${ }^{[1-3]}$, improve the hot workability ${ }^{[4-7]}$ and the powder metallurgy processing ${ }^{[8,9]}$, especially in respect of microstructure $^{[10,11]}$ and mechanical properties ${ }^{[12]}$. Thus, THP provides a feasible way to expand the usage of diffusion bonding with titanium alloys. Until now, titanium thermohydrogen processing technology has became a special research field ${ }^{[12-14]}$. The studies on diffusion bonding of hydrogenated titanium mostly make use of the press machine to supply pressure ${ }^{[1,2]}$, but seldom use gas pressure which is prevalent in SPF/DB technology $y^{[3]}$. In this paper, diffusion bonding experiment was carried out using gas pressure and the research mostly focused on the welding rate of hydrogenated Ti-6Al-4V alloy.

\section{Experiment}

The materials used in this research were Ti-6Al-4V alloy plate with hydrogen contents of $0,0.11 \%, 0.32 \%, 0.48 \%$ (mass fraction), respectively and the commercially pure titanium plate with $0,0.13 \%$, which were hydrogenated at $750{ }^{\circ} \mathrm{C}$ for $1 \mathrm{~h}^{[7]}$. The hydrogenated Ti-6Al-4V alloy and commercially pure titanium were cut into the rectangular specimens with dimensions of $45 \mathrm{~mm} \times 20 \mathrm{~mm} \times 2 \mathrm{~mm}$. They were cleaned ultrasonic alloy with acetone, then packaged by TIG welding using two stainless steel plates of $140 \mathrm{~mm} \times 140 \mathrm{~mm} \times 0.6 \mathrm{~mm}$ dimensions. The package edge had an $5 \mathrm{~mm}$ gap used to weld (TIG) a stainless pipe to vacuum the package in the experiment. The package and the mold used in experiment are showed in Fig.1. The diffusion bonding was carried out in the SPF/DB furnace with a heating rate $4{ }^{\circ} \mathrm{C} \cdot \min ^{1}$. When the temperature reached $600{ }^{\circ} \mathrm{C}$, the vac-

Received date: February 20, 2013

Corresponding author: Hou Hongliang, Ph. D., Professor, Beijing Aeronautical Manufacturing Technology Research Institute, Beijing 100024, P. R. China, Tel: 0086-10-85701254,E-mail: hou_h1@163.com 


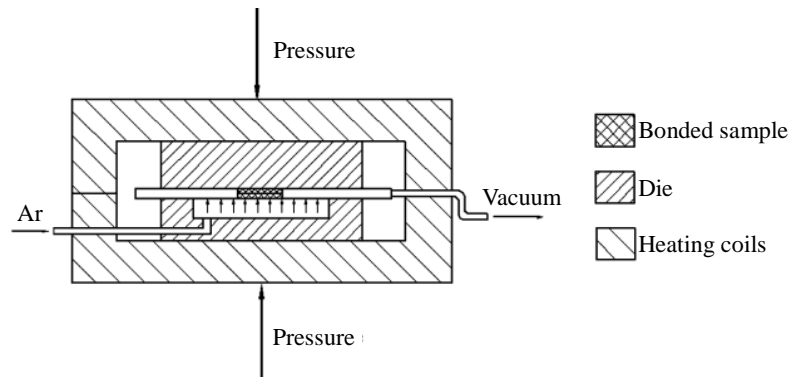

Fig.1 The assembly for gas diffusion bonding

uum pump was turned off in order to avoid hydrogen escaping from specimens. The target temperature was held for $30 \mathrm{~min}$ then the mold was filled with gas $\mathrm{Ar}_{2}$ under a pressure of 1.5 $\mathrm{MPa}$ for $1 \mathrm{~h}$. Once the furnace was cooled to $500{ }^{\circ} \mathrm{C}$, the package was taken out and cooled in air. The experiment was repeated in the temperature range of $800 \sim 860{ }^{\circ} \mathrm{C}$. After diffusion bonding, dehydrogenation test was carried out in a vacuum furnace and the hydrogen contents were determined by weighing the specimens before and after dehydrogenation using high-accuracy scale with the accuracy of $10^{-5} \mathrm{~g}$. The materials and diffusion bonding joints were observed by optical microscope $(\mathrm{OM})$ and scanning electron microscopy (SEM). The elemental compositions were determined by electron probe micro-analyzer (EPMA).

\section{Results and Discussion}

\subsection{Microstructure morphology}

The microstructures of as-received and hydrogenated Ti-6Al-4V alloy are shown in Fig.2. it can be seen that the microstructure of as-received Ti-6Al-4V alloy is equiaxial and composed of primary $\alpha$ phase and grain boundary $\beta$ phase. For the alloy with $0.11 \% \mathrm{H}$, its original morphology is kept the same with the as-received, only the colors of $\alpha$ phase and $\beta$ phase change, they are uneasy to distinguish (sample has the original morphology but the colors of $\alpha$ phase and $\beta$ phase are uneasy to distinguish). With the increase of the hydrogen content, the colors of etched $\alpha$ phase and $\beta$ phase reverse at $0.32 \% \mathrm{H}$ just like what the literature [7] indicated, meanwhile, the equiaxial microstructure transforms to duplex microstructure. The volume fraction of $\beta$ phase increases with higher hydrogen content. The sample with $0.48 \% \mathrm{H}$ shows that darkcolored $\alpha$ phase is surrounded by light-colored $\beta$ phase. It can be inferred that $\beta$ phase is more stable in hydrogenated samples than that in as-received at high temperature.

\subsection{Bonding rate and microstructure evolution}

Diffusion bonding rate is an important indicator of bonding quality especially for $\mathrm{DB}$ of the titanium alloy sheet in SPF/DB Process. The bonding rate can be calculated by formula (1):

$$
L=\frac{L_{1}}{L_{0}}
$$

where $L, L_{1}, L_{0}$ are bonding rate (\%), unwelding length in the

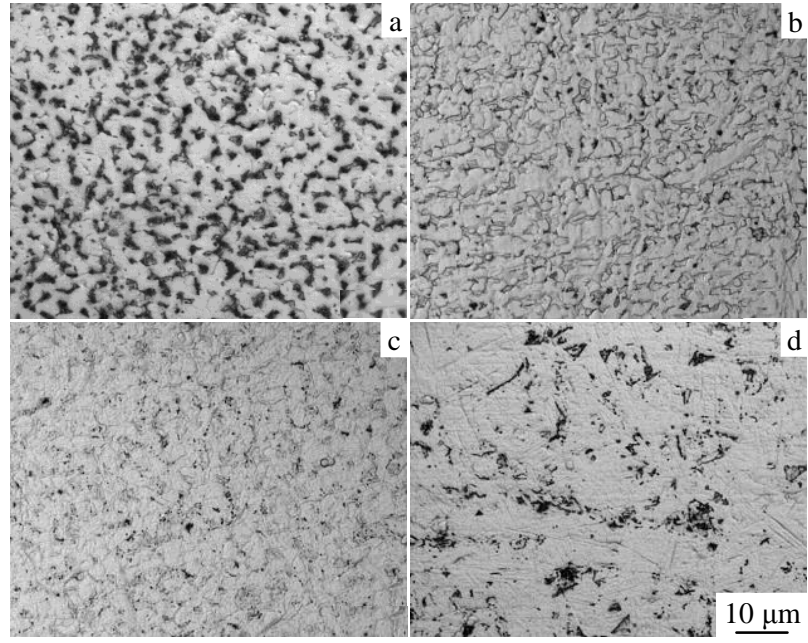

Fig.2 Microstructures of the Ti-6Al-4V alloys: (a) as-received, (b) $0.11 \% \mathrm{H},($ c) $0.32 \% \mathrm{H}$, and (d) $0.48 \% \mathrm{H}$

interface, and the length of interface, respectively.

The typical interface of diffusion bonding under $1.5 \mathrm{MPa}$ gas pressure for $60 \mathrm{~min}$ at $800{ }^{\circ} \mathrm{C}$ is presented in Fig. 3 and those at $840{ }^{\circ} \mathrm{C}$ are shown in Fig.4. Fig. 5 shows the bonding rate of as-received and hydrogenated samples as functions of hydrogen content. With the rise of diffusion bonding temperatures, the bonding rate of the interface first increases then decreases. The samples with $0.11 \% \mathrm{H}$ have the maximum bonding rates at any temperature while the bonding rates of the samples with $0.48 \% \mathrm{H}$ are lower than those of as-received materials at 800 and $820{ }^{\circ} \mathrm{C}$. It can be seen from Fig.3a shows that as-received sample at $800{ }^{\circ} \mathrm{C}$ gets only $45 \%$ of bonding rate and the interface has lots of long voids. When the bonding rate increases to $69 \%$ at $840{ }^{\circ} \mathrm{C}$ (Fig.4a), the grains are formed at the interface with distributing oval and round voids. When the bonding rate of the sample with $0.11 \% \mathrm{H}$ gets $68 \%$ at $800{ }^{\circ} \mathrm{C}$ (Fig.3b), it is similar with the as-received sample at $840{ }^{\circ} \mathrm{C}$. However, the samples with $0.32 \% \mathrm{H}$ and $0.48 \% \mathrm{H}$ at $840{ }^{\circ} \mathrm{C}$ only get $50 \%$ and $34 \%$ of bonding rate, respectively. The results indicate that at lower temperature and under low bonding pressure, high hydrogen content plays a minor role in the closing of voids, even slows down the closing of voids. In addition, at $840{ }^{\circ} \mathrm{C}$, the bonding rate of the sample with $0.11 \%$ $\mathrm{H}$ reaches $95 \%$ and the voids disappear. Meanwhile, the bonding rates of the samples with $0.32 \% \mathrm{H}$ and $0.48 \% \mathrm{H}$ all reach $81 \%$ which is much higher than $69 \%$ of as-received material under the same conditions. The result indicates that at higher temperature and under low bonding pressure, the effect of hydrogen on promoting the closing of voids is more obviously.

\subsection{Diffusion kinetics of elements}

In diffusion bonding, the diffusion coefficients of the alloy elements determine the diffusion distance of atom and the degree of uniformity of the interface. Therefore, the diffusion 
coefficient of elements can provide a theoretical basis for the

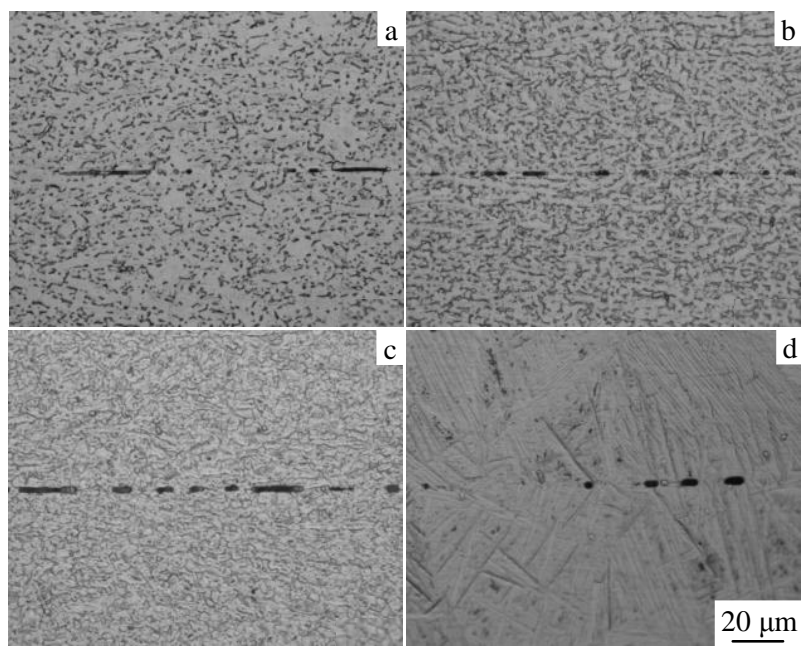

Fig.3 The interface under 1.5 MPa gas pressure for $60 \mathrm{~min}$ at 800 ${ }^{\circ} \mathrm{C}$ : (a) as-received material, (b) $0.11 \% \mathrm{H}$, (c) $0.32 \% \mathrm{H}$, and (d) $0.48 \% \mathrm{H}$

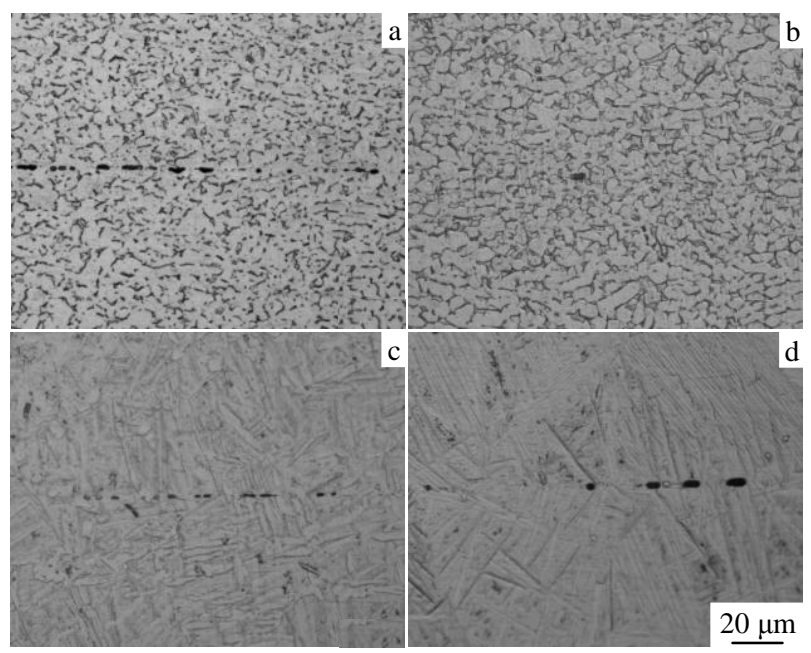

Fig.4 The interfaces under 1.5 MPa gas pressure and $60 \mathrm{~min}$ at 840 ${ }^{\circ} \mathrm{C}$ : (a) as-received material, (b) $0.11 \% \mathrm{H}$, (c) $0.32 \% \mathrm{H}$, and (d) $0.48 \% \mathrm{H}$

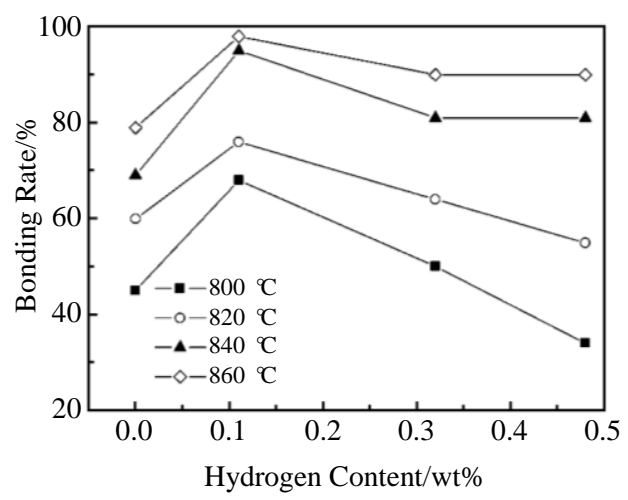

Fig.5 Bonding rate as functions of hydrogen content diffusion bonding. In the experiment, the content of elements at any points in materials change over time in the diffusion process. This unstable state diffusion problem can be solved by the Fick Second Law. If the diffusion coefficient $D$ is constant, the Fick Second Law equation is ${ }^{[15]}$ :

$$
\frac{\partial C}{\partial t}=D \frac{\partial^{2} C}{\partial x^{2}}
$$

Since $D$ is a constant, with the error function solution, which is

$$
C(x, t)=\frac{C_{0}}{2}\left[1-\operatorname{erf}\left(\frac{x}{2 \sqrt{D t}}\right)\right]
$$

where $D, C, C_{0}, t$ are diffusion coefficient, the atomic concentration in $x$, the atomic concentration in base material, diffusion bonding time, respectively. So,

$$
Z=\frac{x}{2 \sqrt{D t}}
$$

according to equation (4) the diffusion coefficient $D$ can be obtained at a certain temperature:

$$
D=\frac{x^{2}}{4 Z^{2} t}
$$

The diffusion bondings of commercially pure titanium and Ti-6Al-4V alloys with $0.11 \% \mathrm{H}$ and without hydrogen were carried out under a gas pressure of $1.5 \mathrm{MPa}$ at $840{ }^{\circ} \mathrm{C}$ for 60 min, and the interface is positioned verticality in both SEM images in Fig.6. As is shown in Fig.6a, it can be seen that only voids are observed in the interface without hydrogen. For comparison, in Fig.6b, a reaction layer are found in the pure titanium side of the sample with $0.11 \% \mathrm{H}$.

Fig.7 shows the distribution of $\mathrm{Al}$ and $\mathrm{V}$ elements in both sides of the interface by points analysis using EPMA. It can be seen that $\mathrm{Al}$ and $\mathrm{V}$ elements diffuse through the interface to the pure titanium. At equal distance from the interface, the concentration of $\mathrm{Al}$ and $\mathrm{V}$ elements are obviously higher than that without hydrogen. With the increase of diffusion distance, $\mathrm{V}$ atomic concentration is almost unchanged while the Al molar concentration decreases. This shows that the reaction layer is rich in $\mathrm{V}$ element. It can be inferred that the diffusion of $\mathrm{V}$ element which is an $\beta$-phase stabilizing element induces the transformation of $\alpha$-phase to $\beta$-phase, so the reaction layer is light-colored area under SEM.

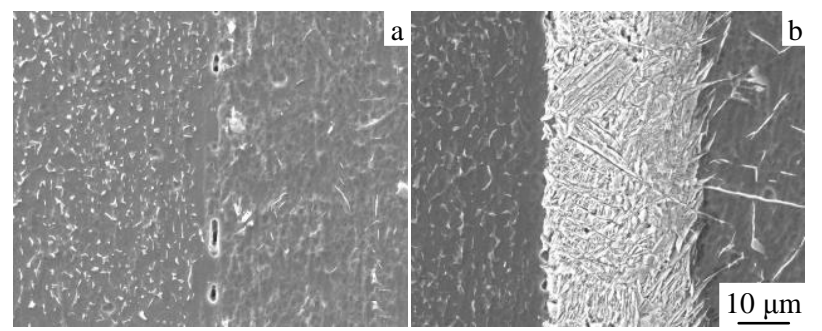

Fig.6 SEM images of the interfaces: (a) Ti-6Al-4V and pure 
titanium; (b) Ti-6Al-4V and pure titanium with $0.11 \% \mathrm{H}$
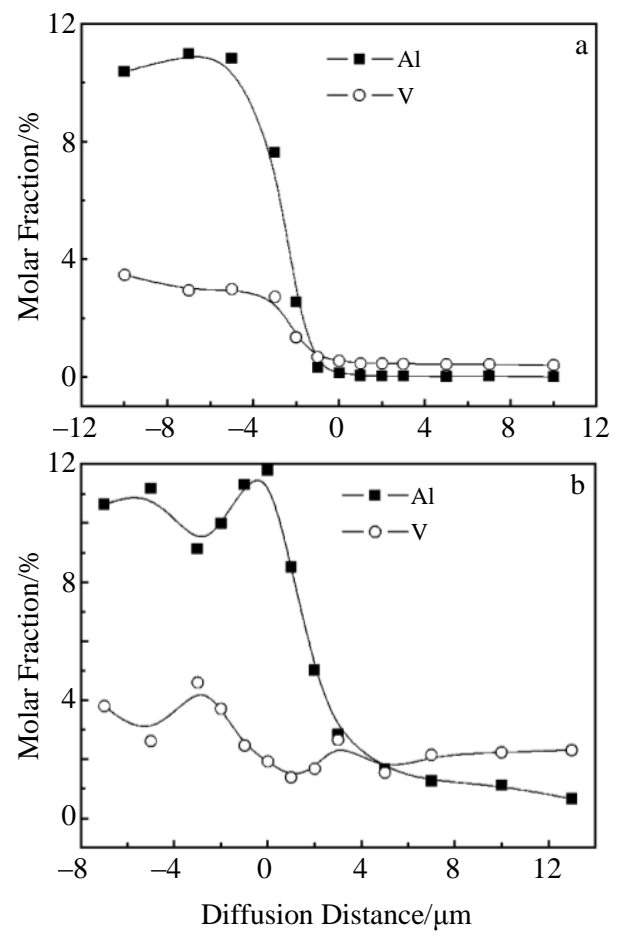

Fig.7 Distribution of $\mathrm{Al}$ and $\mathrm{V}$ elements in both sides of the interface: (a) Ti-6Al-4V and pure titanium;

(b) Ti-6Al-4V and pure titanium with $0.11 \% \mathrm{H}$

Table 1 shows the average diffusion coefficients of $\mathrm{Al}$ and $\mathrm{V}$ elements according to equation (4) in pure titanium at $840{ }^{\circ} \mathrm{C}$. The results show that the diffusion coefficient of $\mathrm{V}$ atoms is much higher than that of $\mathrm{Al}$ atoms in $\alpha$-phase while the diffusion coefficients of $\mathrm{V}$ atoms and $\mathrm{Al}$ atoms increases by one order of magnitude after the sample is hydrogenated with $0.11 \% \mathrm{H}$. The effect of weak-bond induced by hydrogen can reduce the vacancy formation energy and the vacancy migration energy in Ti substrate. Thus, the bonding rate increases as the self diffusion coefficient of Ti and the diffusion coefficients of solute atoms such as $\mathrm{V}$ and $\mathrm{Al}$ increase.

Table 1 Diffusion coefficient of $\mathrm{V}$ and $\mathrm{Al}$ atoms in $\alpha$-phase at $840{ }^{\circ} \mathrm{C}$

\begin{tabular}{ccccc}
\hline \multirow{2}{*}{ Phase } & $\begin{array}{c}\text { Hydrogen } \\
\text { content/wt\% }\end{array}$ & Time/s & \multicolumn{2}{c}{ Diffusion coefficient $/ \mathrm{cm}^{2} \cdot \mathrm{s}^{-1}$} \\
\cline { 4 - 5 }$\alpha-\mathrm{Ti}$ & 0 & 3600 & $3.042 \times 10^{-16}$ & $1.700 \times 10^{-15}$ \\
& 0.11 & 3600 & $6.370 \times 10^{-15}$ & $3.326 \times 10^{-14}$ \\
\hline
\end{tabular}

\section{Conclusions}

1) The appropriate amount of hydrogen can increase the rate of diffusion bonding. The bonding rate of the sample with $0.11 \% \mathrm{H}$ is $68 \%$, its diffusion bonding temperature is reduced by $40{ }^{\circ} \mathrm{C}$ compared to original samples.

2) Low content of hydrogen can maintain Ti-6Al-4V equiaxed microstructure after bonding. However, high content of hydrogen will induce coarse Widmanstatten microstructure after bonding.

3) The diffusion coefficients of $\mathrm{V}$ and $\mathrm{Al}$ atoms increase while the sample is hydrogenated with $0.11 \% \mathrm{H}$. The improved performance of diffusion bonding mainly attributed to the effect of weak-bond and the increased diffusion coefficient of elements induced by hydrogen.

\section{References}

1 Liu H, Cao J, He P et al. Int J Hydrogen Energy[J], 2009, 34(2): 1108

2 Feng J C, Liu H, He P et al. Int J Hydrogen Energy[J], 2007, 32(14): 3054

3 Wang Xiaoli, Zhao Yongqing, Hou Hongliang et al. J Alloy Compd[J], 2010, 503(1): 151

4 Senkov O N, Jonas J J. Metall Mater Trans A[J], 1996, 27(7): 1869

5 Zong Y Y, Shan D B, Lu Y et al. Int J Hydrogen Energy[J], 2007, 32(16): 3936

6 Li M Q, Zhang W. Int J Hydrogen Energy[J], 2008, 33(11): 2714

7 Lu Junqiang, Qin Jining, Lu Weijie et al. Mater Sci Eng A[J], 2009, 500(1-2): 1

8 Apgar L S, Eylon D. ISIJ International[J], 1991, 31(8): 915

9 Kao W H, Orsborn L M. In: Froes FH, Smugeresky J E ed. Powder Metallurgy of Titanium Alloys[C]. Warrendale, PA: TMS-AIME, 1980: 163

10 Yoshimura H, Nakahigashi J. Int J Hydrogen Energy[J], 2002, 27(7-8): 769

11 Murzinova M A, Salishchev G A, Afonichev D D. Int J Hydrogen Energy[J], 2002, 27(7-8): 775

12 Senkov O N, Froes F H. Int J Hydrogen Energy[J], 1999, 24(6): 565

13 Eliaz N, Eliezer D, Olson D L. Mater Sci Eng[J], 2000, A289: 41

14 Goltsov V A. Int J Hydrogen Energy[J], 2002, 27(7-8): 845

15 Suardi K, Hamzah E, Ourdjini A et al. J Mater Process Technol[J], 2007, 185(1-3): 106 


\title{
氢对 Ti-6Al-4V 合金扩散连接行为与机理的影响
}

\author{
李志强 ${ }^{1,2}$, 韩 坤 $^{2}$, 侯红亮 ${ }^{2}$, 王宝雨 ${ }^{1}$, 胡正睘 ${ }^{1}$ \\ (1. 北京科技大学, 北京 100083) \\ (2. 北京航空制造工程研究所, 北京 100024)
}

\begin{abstract}
摘 要: 研究了置氢 Ti-6AL-4V 合金在 $800 \sim 860{ }^{\circ} \mathrm{C}$ 温度范围内气压扩散连接行为与机理。在 $840{ }^{\circ} \mathrm{C}$ 对置氢 $0.11 \%$ (质量分数, 下同) 的纯钛和 Ti-6AL-4V 合金进行了扩散连接。应用光学显微镜 (OM)、扫描电子显微镜 (SEM) 和电子探针显微分析仪 (EPMA) 研究 了氢对扩散连接接头焊合率及元素扩散行为的影响。结果表明：氢能够显著提高扩散连接接头的焊合率（置氢 $0.11 \%$ 在 $840{ }^{\circ} \mathrm{C}$ 的焊合率 大于 $98 \%)$; 氢含量为 $0.11 \%$ 的 Ti-6Al-4V 合金扩散连接后仍为等轴组织, 而高氢含量 $(0.32 \%$ O.48\%H) Ti-6Al-4V 合金扩散连接后组织 转变为粗大的魏氏组织; 氢对扩散连接行为的改善作用主要是由于氢的弱键效应及其对元素扩散系数的提高; 相对于未置氢 Ti-6Al-4V 合金, $0.11 \%$ 的氢能够将 $\mathrm{Al}$ 和 $\mathrm{V}$ 元素的扩散系数提高一个数量级, 并使扩散连接温度降低了 $40{ }^{\circ} \mathrm{C}$ 。
\end{abstract}

关键词: 氢; Ti-6Al-4V; 扩散连接

作者简介: 李志强, 男, 1965 年生, 研究员, 北京航空制造工程研究所, 北京 100024, 电话: 0086-10-85701254, E-mail: zqlee@126.com 